\title{
Milk protein consumption improves muscle performance and total antioxidant status in young soccer athletes: a randomized controlled trial
}

\author{
Muhammad Irwan Setiawan, ${ }^{1}$ Hardhono Susanto, ${ }^{2}$ Martha Irene Kartasurya ${ }^{3}$
}

pISSN: 0853-1773 - elSSN: 2252-8083 https://doi.org/10.13181/mji.oa.202872 Med J Indones. 2020;29:164-71

Received: August 17, 2018 Accepted: April 05, 2020

\section{Authors' affiliations:}

${ }^{1}$ Master Program for Nutrition Science, Faculty of Medicine, Universitas Diponegoro, Semarang, Indonesia, ${ }^{2}$ Department of Anatomy and Physiology, Faculty of Medicine, Universitas Diponegoro, Semarang, Indonesia, ${ }^{3}$ Department of Public Health Nutrition, Faculty of Public Health, Universitas Diponegoro, Semarang, Indonesia

\section{Corresponding author:}

Muhammad Irwan Setiawan

Master Program for Nutrition Science,

Faculty of Medicine, Universitas

Diponegoro, Jalan Prof. H. Soedarto, SH

- Tembalang - Semarang, Central Java

50275, Indonesia

Tel/Fax: +62-24-76402666;

$+62-24-76402881 ;+62-24-7602329 /$

$+62-24-76402881$

E-mail: portegeputih@gmail.com

\begin{abstract}
BACKGROUND Muscle performance and antioxidant balance are closely related to an athlete achievement. Milk proteins (whey and casein) contain essential and non-essential amino acids, which benefit muscle performance through increased antioxidant levels. This study was aimed to evaluate the effects of milk protein on muscle performance and total antioxidant status (TAS) in soccer athletes.
\end{abstract}

METHODS A randomized controlled trial was conducted on 20 males 16- to 18-year-old athletes at the Central Java Soccer Club in January 2018. For 28 days, the treatment group received $24 \mathrm{~g} / \mathrm{d}$ of milk protein and the control group received $24 \mathrm{~g} / \mathrm{d}$ of maltodextrin. Muscle performance was measured through a 20-m sprint, shuttle run, Illinois run, standing broad jump, sit-ups, push-ups, sit-and-reach test, and onerepetition maximum ( $1 \mathrm{RM}$ ) leg extension. TAS was analyzed using the 2,2-azino-bis-3ethylbenzothiazoline-6-sulfonic acid (ABTS) method.

RESULTS The treatment group had a decreased shuttle run time (-0.16 [0.11] versus 0.08 [0.14] sec), greater increase in sit-ups (6.80 [2.57] versus 1.10 [2.84] times/60 sec), greater increase in push-ups (2.40 [1.78] versus 0.30 [1.77] times/60 sec), and greater increase in 1RM leg extension (32.00 [13.78] versus 3.50 [13.75] kg). After adjustments for age, energy intake, carbohydrates, and pre-interventional performance, these parameters remained significantly improved after the intervention of milk protein. The TAS increase was greater in the treatment group than in the control group $(0.36$ [0.32] versus -0.12 [0.20] mmol/l) before and after adjustment for age, vitamin $C$, iron, selenium intake, and TAS pre-treatment.

CONCLUSIONS Milk protein supplementation for 28 days increased muscle performance and TAS.

KEYWORDS milk proteins, muscles, soccer
Soccer is one of the most popular sports in the world and in Indonesia. ${ }^{1}$ It is an endurance sport that requires muscle coordination, particularly of the lower extremities, through leaping, sprinting, abrupt stopping, tackling, and other specific movements; therefore, players must have a high athletic performance. $^{2}$ Strength, speed, and endurance are essential abilities of athletic performance and thus affect whether athletes reach the soccer championships. ${ }^{3}$ A study by the Indonesian National Soccer Association (PSSI) showed that Indonesian soccer athletes' performance decreased after $60 \mathrm{~min}$ of a game. One of the causes was the reduction of muscle performance, as evidenced by a slower sprint time. Sprint time is an important part of the game and directly contributes to dribbling and scoring goals. ${ }^{4,5}$ 
The decrease in muscle performance was also caused by muscle fatigue due to decreased muscle strength. Increased reactive oxygen species (ROS) production can decrease muscle strength and simultaneously become an indicator of muscle fatigue. ${ }^{6}$ Antioxidant and prooxidant levels are important for optimal recovery. ${ }^{6}$ During exercise, muscle tissue produces ROS in large quantities, resulting in oxidative stress that leads to health problems. ${ }^{7}$ ROS overproduction induces damage in all cellular macromolecules (such as lipids, proteins, and DNA).

Milk proteins contain both whey and casein proteins, which are known as functional foods that have a direct impact on an athlete's health. Milk proteins provide almost all of the necessary amino acids, particularly the essential amino acids (EAAs) that can create a positive net protein balance to prevent muscle damage and increase muscle anabolism. Functional adaptations such as strength improvements also occur after consuming EAAs. EAA intake can also improve a lower extremity strength. ${ }^{8}$ Milk protein consumption increased muscle strength, as shown in increasing one-repetition maximum (1RM) leg press, 1RM squat, and 1RM bench press.9-11 Furthermore, milk protein can reduce muscle fatigue. Decreased muscle fatigue during resistance training is a result of increased muscle buffer capacity after milk protein consumption. ${ }^{12}$

Branched-chain amino acids (BCAAs) such as valine, leucine, and isoleucine may contribute to the mechanism of antioxidant systems. Studies on BCAA interventions can modulate the expression of genes involved in antioxidant defenses, such as superoxide dismutase (SOD) 1 and 2, catalase (CAT), and glutathione peroxidase 1 (GPX1) in mice. The amino acid profiles of sulfur-containing milk proteins, such as cysteine and taurine, may act as sulfhydryl donor groups to reduce intracellular glutathione concentrations induced during exercise..$^{13}$ This mechanism is generally known to increase glutathione concentration caused by increased plasma antioxidant capacity to allow aerobic metabolism without causing damage due to ROS accumulation while maintaining homeostatic reduction and oxidation. ${ }^{14}$ Furthermore, the glutamine content of whey protein may act as an immunomodulator through another mechanism, such as the I-glutamine-glutathione axis. These results suggest that milk protein administration muscle affects strength, endurance, and antioxidant status. This randomized controlled trial was aimed to analyze the effect of milk protein supplementation on muscle performance and total antioxidant status (TAS) in soccer athletes.

\section{METHODS}

This randomized controlled trial was performed in a soccer club in Central Java during January 2018 (Figure 1). This study has received approval from the Research Ethics Committee of the Faculty of Medicine of Universitas Diponegoro (No. 81/EC/FK-RSDK/II/2018). Informed consent was obtained from the study participants after they received an explanation about the intervention.

\section{Subjects enrollment}

The inclusion criteria were subjects performed routine physical exercise at least 5 times/week for 1.5 hours each time, had a normal body fat percentage $(<20 \%)$, were not taking any antioxidant or multivitamin supplements during the intervention, had no injuries, and were not undergoing medical treatment. Twenty soccer athletes aged 16-18 years old who fulfilled the inclusion criteria were randomly assigned using simple lottery randomization into the treatment and control groups, each of which consisted of 10 subjects. During the 28-day intervention, the treatment group received $24 \mathrm{~g} / \mathrm{d}$ of milk protein (Ultimate Nutrition Inc., USA) and the control group received $24 \mathrm{~g} / \mathrm{d}$ of maltodextrin (Ultimate Nutrition Inc.) in $300 \mathrm{ml}$ of water. The milk protein consists of $24 \mathrm{~g}$ protein, $1 \mathrm{~g}$ fat, $40 \mathrm{mg}$ cholesterol, $2 \mathrm{~g}$ carbohydrate, $2 \mathrm{~g}$ sugars, 100 $\mathrm{mg}$ sodium, $140 \mathrm{mg}$ calcium, and $160 \mathrm{mg}$ potassium. The taste of both products was similar and the subjects were blinded to group allocation. All subjects were allowed to consume any type of foods during the intervention period, except supplementations.

\section{Variables measurements}

Data on sociodemographic characteristics, smoking habits, and 4 days ( 2 active days and 2 leisure days) of 24-hour dietary recall were taken at baseline and obtained through interviews using structured questionnaires. Physical activity level (PAL) data were obtained by self-reporting. Dietary data were analyzed using the NutriSurvey program, and the nutritional adequacy level was calculated using the Harris 


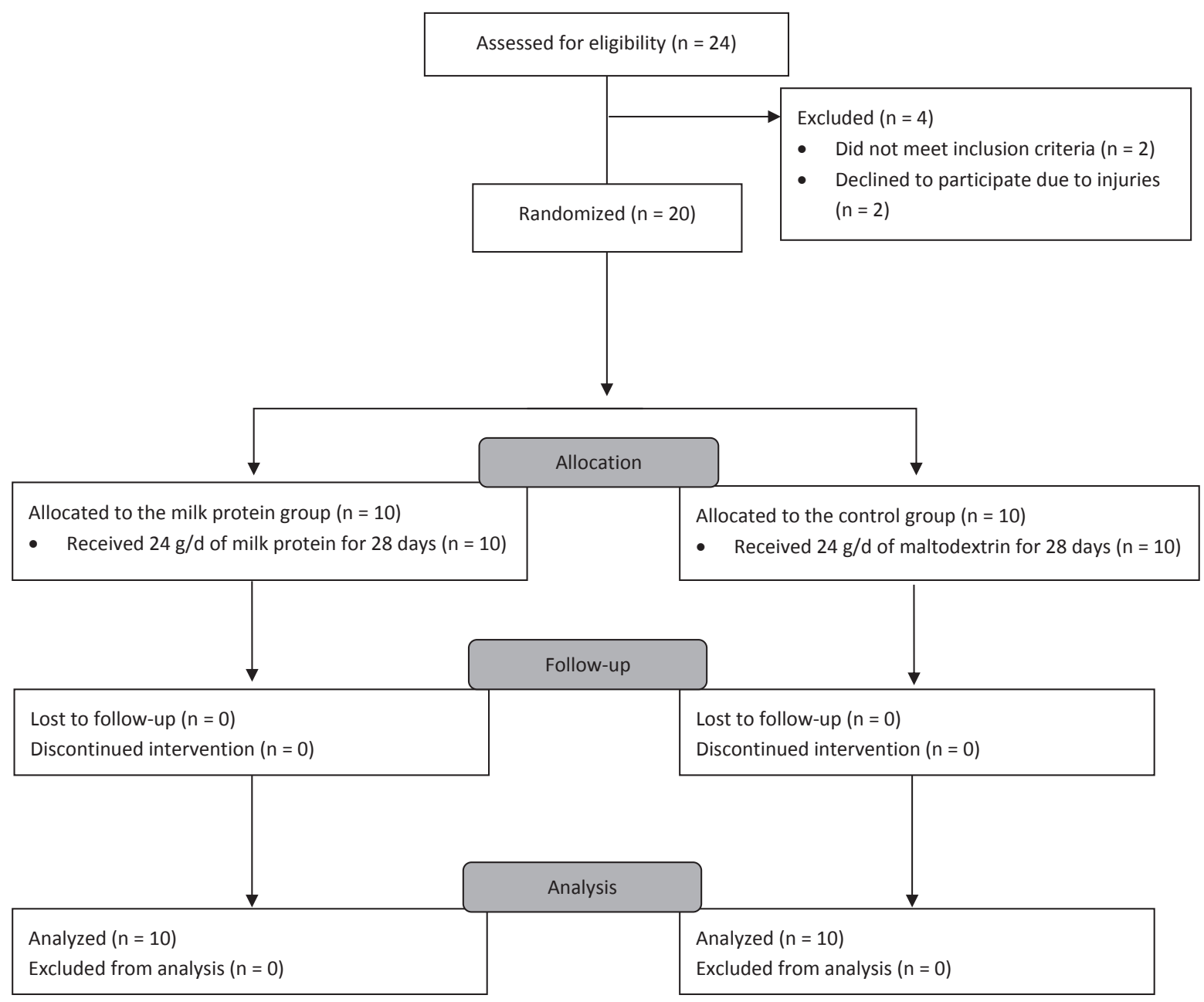

Figure 1. CONSORT trial flow diagram for the study

Benedict formula. The level of adequacy was assessed as the amount of intake in a day compared with individual needs and was calculated as a percentage. ${ }^{15}$ Anthropometric data on height was measured using a stature meter. Weight and percent body fat were measured with Tanita $^{\circledR}$ Body Fat Monitor, which is within $\pm 5 \%$ accuracy of the institutional standard for body composition analysis. The PAL and nutritional adequacy were assessed during the interventional period. All these data were taken by independent interviewer.

Muscle performance was measured using the Asian Committee for Standardization of Physical Fitness Tests, which consists of: a 20-m sprint to assess speed, a shuttle run to assess speed and agility, Illinois run to assess agility, a standing broad jump to assess strength, push-ups to assess power, sit-ups to assess endurance, the sit-and-reach test to assess flexibility, and a $1 \mathrm{RM}$ leg extension to assess power. ${ }^{16}$ The measurement was carried out by the instructors from student education and training center (Pusat Pendidikan dan Latihan Pelajar/PPLP) pre- and post- 28 days of interventions. The instructors were blinded to group allocation. There was no resistance training during the intervention.

Blood samples ( $5 \mathrm{cc}$ ) were taken intravenously by a health officer pre- and post-treatment. The blood samples were stored in ethylenediaminetetraacetic acid tubes to avoid clumping and then centrifuged at $3,500 \mathrm{rpm}$ for $15 \mathrm{~min}$ to separate the blood plasma. The plasma was separated and quickly frozen at $-80^{\circ} \mathrm{C}$. The plasma was stored for approximately 7 days for the TAS analysis. TAS was assessed based on free radical reduction (ABTSU+ 2,2-azino-bis-3-ethylbenzothiazoline-6-sulfonic acid) by antioxidants and was read at $600 \mathrm{~nm}$ 
absorbance for $3 \mathrm{~min}$ in spectrophotometry. ABTSU+ cations were formed by ABTS interactions with ferrylmyoglobin radical species, which were generated by metmyoglobin activation with hydrogen peroxide. The suppression of ABTSU+ radical cation absorbance by plasma antioxidants was compared with that of ascorbic acid. The result was expressed in $\mathrm{mmol} / \mathrm{l}-$ ascorbate equation. ${ }^{17,18}$

\section{Statistical analysis}

The mean, standard deviation, minimum, and maximum values were described for age, nutritional adequacy, PAL, anthropometry, muscle performance, and TAS. The Shapiro-Wilk test was used to analyze the normality of the variable distributions. Variations in muscle performance (20-m sprint, shuttle run, Illinois run, push-ups, sit-ups, and 1RM leg extension) and TAS pre- and post-intervention was analyzed by a paired t-tests, and sit-and-reach was analyzed by the Wilcoxon tests. A significant difference was determined present when $p<0.05$. Differences between pre- and post-intervention in the mean scores of variables representing muscle performance (20- m sprint, shuttle run, Illinois run, push-ups, sit-ups, and $1 R M$ leg extension), TAS, nutritional adequacy (energy, carbohydrate, protein, fat, vitamin A, vitamin C, vitamin E, zinc, and iron), PAL, and anthropometry in both groups were analyzed by independent $t$-tests; sit-and-reach performance, selenium intake, and age were analyzed by Mann-Whitney $U$ tests. A general linear model was used to control for the confounding variables age, nutritional intake (energy, carbohydrate, and selenium), and PAL on muscle performance and TAS.

\section{RESULTS}

The subjects' characteristics, i.e., age, weight, height, nutritional status (body mass index/age), body fat percentage, and physical activity, are shown in Table 1. The nutritional adequacy level of these subjects were mostly classified as less $<77 \%$. Age was controlled in the multivariate analysis. Nutrient intake pre- and post-treatment is shown in Table 2. Both groups showed similar intakes of energy, carbohydrates, protein, fat, vitamin A, vitamin C,

Table 1. Subject characteristics by study group

\begin{tabular}{lcc}
\hline Variable & Milk protein, mean $(\mathrm{SD})(\mathrm{N}=10)$ & Placebo, mean $(\mathrm{SD})(\mathrm{N}=10)$ \\
\hline Age (years), median (min-max) & $16(16-17)$ & $17(16-18)$ \\
Weight $(\mathrm{kg})$ & $65.38(6.96)$ & $68.81(5.38)$ \\
Height $(\mathrm{cm})$ & $170.15(5.62)$ & $171.85(6.29)$ \\
BMI for age $\left(\mathrm{kg} / \mathrm{m}^{2}\right)$ & $22.54(1.52)$ & $23.34(1.95)$ \\
Body fat (\%) & $15.38(1.77)$ & $15.33(0.94)$ \\
Physical activity (unit) & $2.15(0.15)$ & $2.15(0.10)$ \\
\hline
\end{tabular}

$\mathrm{SD}=$ standard deviation; $\mathrm{BMI}=$ body mass index

Table 2. Nutrient intake pre- and post-interventions

\begin{tabular}{lcccc}
\hline \multirow{2}{*}{ Variable } & \multicolumn{2}{c}{ Milk protein, mean $(\mathrm{SD})(\mathrm{N}=10)$} & \multicolumn{2}{c}{ Placebo, mean $(\mathrm{SD})(\mathrm{N}=10)$} \\
\cline { 2 - 4 } & Pre & Post & Pre & Post \\
\hline Energy (kcal) & $1,815(314)$ & $1,935(314)$ & $1,832(260)$ & $1,924(260)$ \\
Carbohydrate (g) & $227(49.1)$ & $230(49.1)$ & $215(65.0)$ & $239(65.0)$ \\
Protein (g) & $73.2(7.27)$ & $97.2(7.27)$ & $62.6(9.78)$ & $78.8(12.6)$ \\
Fat (g) & $69.1(17.1)$ & $70.1(17.1)$ & $75.3(14.0)$ & $81.1(12.2)$ \\
Vitamin A (mcg) & $502(210)$ & $518(210)$ & $645(222)$ & $534(274)$ \\
Vitamin C (mg) & $22.6(9.80)$ & $27.2(11.3)$ & $21.5(6.84)$ & $19.3(8.27)$ \\
Vitamin E (mg) & $11.7(2.47)$ & $11.4(2.95)$ & $12.7(1.84)$ & $12.5(1.91)$ \\
Zinc (mg) & $7.8(0.87)$ & $7.5(1.12)$ & $7.7(0.72)$ & $7.8(1.14)$ \\
Selenium (mcg) & $19.5(3.33)$ & $17.1(15.9-29.2)$ & $22.2(3.27)$ & $23.1(4.21)$ \\
Iron (mg) & $7.17(0.78)$ & $6.79(1.02)$ & $6.61(1.00)$ & $6.47(0.95)$ \\
\hline
\end{tabular}

$\mathrm{SD}=$ standard deviation 
Table 3. Muscle performance and TAS pre- and post-treatment

\begin{tabular}{|c|c|c|c|c|c|c|}
\hline \multirow{2}{*}{ Variable } & & & \multicolumn{2}{|c|}{ Milk protein } & \multicolumn{2}{|c|}{ Placebo } \\
\hline & & & Mean (SD) & $p$ & Mean (SD) & $p$ \\
\hline \multicolumn{7}{|c|}{ Muscle performance } \\
\hline \multirow{3}{*}{ Speed } & \multirow{3}{*}{ 20-m sprint (sec) } & Pre & $3.34(0.22)$ & \multirow{3}{*}{$<0.001 *$} & $3.33(0.29)$ & \multirow{2}{*}{$0.171 *$} \\
\hline & & Post & $3.22(0.23)$ & & $3.26(0.25)$ & \\
\hline & & Difference & $-0.12(0.06)$ & & $-0.07(0.15)$ & $0.286^{\ddagger}$ \\
\hline \multirow{6}{*}{ Strength } & \multirow{3}{*}{ Standing broad jump (m) } & Pre & $2.20(0.16)$ & \multirow{2}{*}{$<0.001 *$} & $2.33(0.23)$ & \multirow{2}{*}{$0.161^{*}$} \\
\hline & & Post & $2.42(0.17)$ & & $2.41(0.20)$ & \\
\hline & & Difference & $0.22(0.07)$ & \multirow{4}{*}{$<0.001 *$} & $0.08(0.14)$ & $0.053^{\ddagger}$ \\
\hline & \multirow{3}{*}{ 1RM leg extension $(\mathrm{kg})$} & Pre & $92.00(23.35)$ & & $114.00(27.16)$ & \multirow{2}{*}{$0.226 *$} \\
\hline & & Post & 124.00 (23.19) & & $117.50(25.52)$ & \\
\hline & & Difference & $32.00(13.78)$ & & $3.50(13.75)$ & $<0.001^{\ddagger}$ \\
\hline \multirow{6}{*}{ Agility } & \multirow{3}{*}{ Shuttle run (sec) } & Pre & $6.23(0.39)$ & \multirow{2}{*}{$0.002 *$} & $6.23(0.77)$ & \multirow{2}{*}{$0.142^{*}$} \\
\hline & & Post & $6.07(0.39)$ & & $6.31(0.66)$ & \\
\hline & & Difference & $-0.16(0.11)$ & & $0.08(0.14)$ & $0.001^{\ddagger}$ \\
\hline & \multirow{3}{*}{ Illinois run (sec) } & Pre & $17.27(0.75)$ & \multirow{3}{*}{$0.016 *$} & $16.62(0.80)$ & \multirow{2}{*}{$0.411 *$} \\
\hline & & Post & $17.00(0.84)$ & & $16.75(0.78)$ & \\
\hline & & Difference & $-0.27(0.29)$ & & $0.13(0.47)$ & $0.741^{\ddagger}$ \\
\hline \multirow{3}{*}{ Endurance } & \multirow{3}{*}{ Sit up (times/60 sec) } & Pre & $59.90(7.78)$ & \multirow{3}{*}{$<0.001 *$} & $62.00(5.18)$ & \multirow{2}{*}{$0.253^{*}$} \\
\hline & & Post & $66.70(6.94)$ & & $63.10(4.84)$ & \\
\hline & & Difference & $6.80(2.57)$ & & $1.10(2.84)$ & $0.016^{\ddagger}$ \\
\hline \multirow{3}{*}{ Power } & \multirow{3}{*}{ Push up (times/60 sec) } & Pre & $30.40(9.03)$ & \multirow{3}{*}{$0.002 *$} & $30.20(4.54)$ & \multirow{2}{*}{$0.604 *$} \\
\hline & & Post & $32.80(9.4)$ & & 30.50 (4.79) & \\
\hline & & Difference & $2.40(1.78)$ & & $0.30(1.77)$ & $0.035^{\ddagger}$ \\
\hline \multirow{3}{*}{ Flexibility } & & Pre & $18.80(6.14)$ & †רבחם & $20.30(9.27)$ & \% \\
\hline & Sit and reach $(\mathrm{cm})$ & Post & $20.50(5.79)$ & & $21.60(7.47)$ & 0.220 \\
\hline & & Difference & $1.70(2.06)$ & & $1.30(3.16)$ & $0.389^{\S}$ \\
\hline & & Pre & $0.93(0.24)$ & $0005 *$ & $1.00(0.20)$ & $0005 *$ \\
\hline TAS (mmol/l) & & Post & $1.29(0.29)$ & 0.000 & $0.88(0.23)$ & 0.095 \\
\hline & & Difference & $0.36(0.32)$ & & $-0.12(0.20)$ & $0.001^{\ddagger}$ \\
\hline
\end{tabular}

SD=standard deviation; TAS=total antioxidant status

*Pre- and post-intervention analysis (paired t-tests); ${ }^{\dagger}$ pre- and post-intervention analysis (Wilcoxon tests); ${ }^{\ddagger}$ differences between pre- and postintervention (independent $t$-tests); § differences between pre- and post-intervention (Mann-Whitney $U$ tests). Significant at $p<0.05$

vitamin E, zinc, and iron. However, selenium intake was significantly lower in the milk protein group. Adequate protein and vitamin A intake was only reported in six subjects of the milk protein group. These adequate intakes because of the addition of $24 \mathrm{~g}$ protein and $16 \mathrm{mcg}$ vitamin $\mathrm{A}$ in the treatment group.

Muscle performance indicators pre- and postintervention by the study group are shown in Table 3. Both groups were similar at baseline. The milk protein group showed increased muscle performance post-treatment compared with the baseline values. Muscle performance was improved according to improvements in the shuttle run, sit-ups, push-ups, and $1 \mathrm{RM}$ leg extensions in the milk protein group compared with the control group. Overall, the scores of muscle performance in the milk protein group increased compared with the baseline values; however, the scores did not improve for the 20-m sprint, Illinois run, sit-and-reach, and standing broad jump. Additionally, the TAS in the treatment group improved significantly compared with that of the control group (Table 3).

A general linear model was used to analyze the effect of milk protein on muscle performance after adjustment for energy intake, carbohydrate, age, and 
Table 4. Muscle performance and TAS after adjustment for confounding variables

\begin{tabular}{lcccc}
\hline Variable & Milk protein, mean (SE) (N=10) & Placebo, mean (SE) (N = 10) & $p$ & Adjusted $r^{2}$ \\
\hline 1RM leg extension $(\mathrm{kg})$ & $133.47(5.78)$ & $108.03(5.78)$ & $\mathbf{0 . 0 1 9}$ & 0.653 \\
Sit-ups (times/60 sec) & $67.74(0.82)$ & $62.06(0.82)$ & $\mathbf{0 . 0 0 1}$ & 0.873 \\
Push-ups (times/60 sec) & $32.85(0.72)$ & $30.45(0.72)$ & $\mathbf{0 . 0 4 8}$ & 0.934 \\
Shuttle run (sec) & $6.06(0.04)$ & $6.32(0.04)$ & $\mathbf{0 . 0 0 1}$ & 0.965 \\
TAS (mmol/l) & $1.29(0.10)$ & $0.88(0.10)$ & $\mathbf{0 . 0 2 3}$ & 0.382 \\
\hline
\end{tabular}

TAS=total antioxidant status; $\mathrm{SE}=$ standard error; $1 \mathrm{RM}=$ one-repetition maximum

pre-treatment performance. Shuttle run, sit-ups, pushups, and 1RM leg extension still showed an increase after adjusting for energy intake, carbohydrate, age, and muscle performance pre-treatment. In addition, the increase in TAS was higher in the milk protein group than in the control group before and after adjusting for vitamin C, iron, selenium intake, age, and TAS pre-treatment (Table 4). After adjustment with energy intake, carbohydrate, age, and pre-treatment performance, all of these parameters were still significantly increased. TAS improvement was higher in the milk protein group than in the control group before and after adjusting for vitamin C, iron, selenium intake, age, and TAS pre-treatment.

\section{DISCUSSION}

This study shows that consumption of $24 \mathrm{~g}$ protein milk for 28 days can improve muscle performance, such as an increase in 1RM leg extension (power), shuttle run (speed and agility), push-ups (power) and sit-ups (strength and endurance). A similar improvement has been shown in a previous study on 19 basketball athletes. The subjects showed increase in their $1 \mathrm{RM}$ leg press, bench press, vertical jump, standing broad jump, and agility after consuming 24 $\mathrm{g}$ of milk protein for 8 weeks. ${ }^{19,20}$ Improvements in $1 \mathrm{RM}$ bench press and $1 \mathrm{RM}$ squat were also reported in eight healthy subjects after consuming $20 \mathrm{~g}$ of whey protein for 8 weeks. ${ }^{10}$

Milk protein's content, particularly whey, can improve muscle performance by increasing muscle mass. The muscle performance enhancement in the milk protein group, particularly from whey protein, was most likely a result of the larger increase in muscle mass. Increased muscle mass also enhances muscle strength, particularly in $1 \mathrm{RM}$ leg extension test, standing broad jump, push-ups, and sit-ups. This finding was in line with that of Buckley et al, ${ }^{21}$ who reported an increase in strength after whey protein treatment. Whey can improve performance by reducing muscle damage during exercise. Other studies have reported that whey protein supplementation may increase the peak of isometric torque after eccentric sports. ${ }^{22}$ In addition, Lollo et $\mathrm{al}^{23}$ reported that the consumption of $0.5 \mathrm{~g} / \mathrm{kg} /$ day of whey protein hydrolysate showed serum marker reductions of muscle damage in soccer players after 8 weeks of supplementation.

Muscle performance improvement might be caused by the increased phosphorylation of the ribosomal protein S6 (rpS6), which is activated directly after supplementation. The increased phosphorylation occurred with the milk protein supplementation containing BCAAs than with the placebo. ${ }^{24}$ The improved muscle performance was also supported by mTOR mechanisms that control growth in response to nutrients such as amino acids, growth factors such as insulin, insulin-like growth factor-1 (IGF-1), and cellular energy (ATP). The high frequency and duration of exercise with the supplementation of milk proteins containing BCAAs can increase mTOR activity. The increased IGF-1 in the muscle was responsible for the increased mTOR activity. Then, the combination of IGF-1 and insulin increases mTOR activity to increase protein synthesis. ${ }^{24}$ mTOR activity can also be supported by increasing the load during exercise, which activates mTOR and protein synthesis. This mechanism can also limit the activation of excessive nuclear factor kappalight-chain-enhancers of activated $B$ cells to minimize inflammation during exercise. ${ }^{13}$ Therefore, muscle performance can be enhanced by the consumption of amino acids through phosphorylation by rpS6, mTOR activation, and exercise intensity. ${ }^{25}$

Some confounding variables such as energy, macro nutrition, physical activity, nutritional status, and fat mass might contribute to improved performance, 
although only energy and carbohydrates were shown to be contributors in this study. Fat intake is reserved as the source of energy when carbohydrates depleted. Protein intake is also very important for providing metabolic building blocks for muscles, enzymes, and other body tissues. Additional protein is necessary for an athlete to maintain a positive protein balance, improve recovery, and support muscle growth for a better exercise performance. Exercise performance is also highly determined by fat mass and nutritional status. $^{26}$

Our study differed from other studies in which the intervention was provided for 4 weeks without adding resistance training. The subjects only performed their regular three-hour workout at the PPLP. The lack of additional training was likely one cause of the failure to increase the $20-\mathrm{m}$ sprint speed, standing broad jump, sit-and-reach test, and Illinois run test in the treatment group. Additional training in the treatment group might be necessary to produce the best performance, which was demonstrated in the studies of Naclerio et al, ${ }^{10}$ Wilborn et al, ${ }^{19}$ and Taylor et $\mathrm{al}^{20}$ who added resistance training during supplementation with milk proteins. The results showed that there were increases in strength, power, and agility indicators. These results were related to positive exercise adaptations due to the increased daily protein intake of milk protein. Bosse and Dixon ${ }^{27}$ conducted a meta-analysis which suggested that exercise adaptation could be increased by resistance exercises and an increased daily protein intake of up to $66.1 \%$ more.

The increased TAS in this study could be explained by the increase of glutathione in the casein protein content. Increased glutathione concentrations in the body might improve plasma antioxidant status. This mechanism occurs in the aerobic metabolism system without causing damage due to ROS accumulation while maintaining reduction and oxidation homeostatic. Glutathione is also useful as a detoxification agent. Thus, plasma glutathione concentrations in casein may provide greater protection against a variety of environmental factors. ${ }^{14}$ Another mechanism of increased antioxidants by milk proteins occurs through BCAA compositions (leucine, valine, and isoleucine). Studies show that BCAA administration may increase the expression of genes involved in antioxidant defenses, such as SOD 1 and 2, CAT, and GPx1. Amino acid profiles in sulfur-containing milk proteins, such as cysteine and taurine, can function as sulfhydryl donor groups to reduce the reduction of intracellular glutathione concentrations induced during exercise. In addition, the amino acid content of glutamine in milk proteins can act as an immunomodulator through other mechanisms, such as the I-glutamineglutathione axis. ${ }^{13}$

In addition to a protein intake, multivitamin are likely increasing TAS, although this hypothesis was not proven. Ascorbic acid is a reducing agent that can reduce or neutralize ROS such as hydrogen peroxide. Vitamin $E$ in the form of a-tocopherol functions as a lipid-soluble antioxidant and as membrane protection from lipid radical oxidation produced by lipid peroxidation. Moreover, $a$-tocopherol produces an oxidized toxic peroxide, which can be recycled into its active reduced form through reduction by other antioxidants, such as ascorbic acid, retinol, or ubiquinol..$^{28}$

Changes in fat mass and muscle thickness were not measured in this study; thus, this study is limited in those areas. Both of those variables can help assess muscle performance. Neither group added specific exercises such as resistance exercises, which has been performed in some previous studies. The treatment duration of this study was only 28 days, which may also play a role in the lack of improvement in overall muscle performance. In addition, the antioxidant contents of foods such as flavonoids, carotenoids, isoflavones, and other antioxidant sources cannot be controlled. These antioxidant sources may have affected on increasing the TAS.

In conclusion, milk proteins can improve muscle performance and TAS in soccer athletes. Further research that assesses interventions which last longer than 4 weeks to maximize muscle performance. Variable changes in fat mass and muscle thickness can be added to help assess changes in muscle performance is necessary. Some antioxidant biomarkers such as glutathione, SOD, CAT, GPX, and other biomarkers should also be assessed to understand the specific types of antioxidants in soccer athletes.

\section{Conflict of Interest}

The authors affirm no conflict of interest this study.

\section{Acknowledgment}

The authors would like to thank the PPLP soccer athletes for participating in this study. 
Funding Sources None.

\section{REFERENCES}

1. Seabra A, Katzmarzyk P, Carvalho MJ, Seabra A, Coelho E-Silva M, Abreu S, et al. Effects of 6-month soccer and traditional physical activity programmes on body composition, cardiometabolic risk factors, inflammatory, oxidative stress markers and cardiorespiratory fitness in obese boys. J Sports Sci. 2016;34(19):1822-9.

2. Russell M, Sparkes W, Northeast J, Cook CJ, Bracken RM, Kilduff LP. Relationships between match activities and peak power output and creatine kinase responses to professional reserve team soccer match-play. Hum Mov Sci. 2016;45:96-101.

3. Bompa T, Buzzichelli C. Periodization training for sports. 3rd ed. Champaign: Human Kinetics; 2015. p. 7-9.

4. Peñailillo L, Espíldora F, Jannas-Vela S, Mujika I, Zbinden-Foncea $\mathrm{H}$. Muscle strength and speed performance in youth soccer players. J Hum Kinet. 2016;50:203-10.

5. Svensson K, Alricsson M, Karnebäck G, Magounakis T, Werner S. Muscle injuries of the lower extremity: a comparison between young and old male elite soccer players. Knee Surg Sports Traumatol Arthrosc. 2016;24(7):2293-9.

6. Mello R, Mello R, Gomes D, Paz GA, Nasser I, Miranda H, et al. Oxidative stress and antioxidant biomarker responses after a moderate-intensity soccer training session. Res Sports Med. 2017;25(3)322-32.

7. Perrea A, Vlachos IS, Korou LM, Doulamis IP, Exarhopoulou K, Kypraios $\mathrm{G}$, et al. Comparison of the short-term oxidative stress response in national league basketball and soccer adolescent athletes. Angiology. 2014;65(7):624-9.

8. Vieillevoye S, Poortmans JR, Duchateau J, Carpentier A. Effects of a combined essential amino acids/carbohydrate supplementation on muscle mass, architecture and maximal strength following heavy-load training. Eur J Appl Physiol. 2010;110(3):479-88.

9. Wilborn CD, Outlaw JJ, Mumford PW, Urbina SL, Hayward $S$, Roberts MD, et al. A pilot study examining the effects of 8-week whey protein versus whey protein plus creatine supplementation on body composition and performance variables in resistance-trained women. Ann Nutr Metab. 2016;69(3-4):190-9.

10. Naclerio F, Seijo-Bujia M, Larumbe-Zabala E, Earnest CP. Carbohydrates alone or mixing with beef or whey protein promote similar training outcomes in resistance training males: a double-blind, randomized controlled clinical trial. Int J Sport Nutr Exerc Metab. 2017;27(5):408-20.

11. West DWD, Abou Sawan S, Mazzulla M, Williamson E, Moore DR. Whey protein supplementation enhances whole body protein metabolism and performance recovery after resistance exercise: a double-blind crossover study. Nutrients. 2017;9(7):735.

12. Pasiakos SM, Lieberman HR, McLellan TM. Effects of protein supplements on muscle damage, soreness and recovery of muscle function and physical performance: a systematic review. Sport Med. 2014;44(5):655-70.

13. Cruzat VF, Krause M, Newsholme P. Amino acid supplementation and impact on immune function in the context of exercise. J Int Soc Sports Nutr. 2014;11:61.
14. Deth R, Clarke A, Ni J, Trivedi M. Clinical evaluation of glutathione concentrations after consumption of milk containing different subtypes of $\beta$-casein: results from a randomized, cross-over clinical trial. Nutr J. 2016;15:82.

15. Gibson RS. Principles of nutritional assessment. 2nd ed. New York: Oxford University Press; 2005.

16. Simri $U$, Wingate $M$. Proceedings of the ACSPFT and the ICSPFT - 1972: Wingate Institute, August 1972, Deutsche Sporthochschule Cologne, August 1972. In: Proceedings of the ACSPFT and the ICSPFT - 1972: Wingate Institute, August 1972, Deutsche Sporthochschule Cologne, August 1972. [Netanya, Israel]: Wingate Institute for Physical Education and Sport with the support of the Sport and Physical Education Authority in the Israeli Ministry of Education and Culture; 1972.

17. Ascensão A, Rebelo A, Oliveira E, Marques F, Pereira L, Magalhães J. Biochemical impact of a soccer match - analysis of oxidative stress and muscle damage markers throughout recovery. Clin Biochem. 2008;41(10-11):841-51.

18. Fitriana WD, Fatmawati S, Ersam T. Uji aktivitas antioksidan terhadap DPPH dan ABTS dari fraksi-fraksi daun kelor (Moringa oleifera). Simposium Nasional Inovasi dan Pembelajaran Sains. Bandung; 2015. p. 657-60. Indonesian.

19. Wilborn CD, Taylor LW, Outlaw J, Williams L, Campbell B, Foster CA, et al. The effects of pre- and post-exercise whey vs. casein protein consumption on body composition and performance measures in collegiate female athletes. J Sport Sci Med. 2013;12(1):74-9.

20. Taylor LW, Wilborn C, Roberts MD, White A, Dugan K. Eight weeks of pre-and postexercise whey protein supplementation increases lean body mass and improves performance in Division III collegiate female basketball players. Appl Physiol Nutr Metab. 2015;41(3):249-54.

21. Buckley JD, Thomson RL, Coates AM, Howe PR, DeNichilo MO, Rowney MK. Supplementation with a whey protein hydrolysate enhances recovery of muscle force-generating capacity following eccentric exercise. J Sci Med Sport. 2010;13(1):178-81.

22. Cooke MB, Rybalka E, Stathis CG, Cribb PJ, Hayes A. Whey protein isolate attenuates strength decline after eccentricallyinduced muscle damage in healthy individuals. J Int Soc Sport Nutr. 2010;7:30.

23. Lollo PCB, Amaya-Farfan J, Faria IC, Salgado JVV, Chacon-Mikahil MPT, Cruz AG, et al. Hydrolysed whey protein reduces muscle damage markers in Brazilian elite soccer players compared with whey protein and maltodextrin. A twelve-week in-championship intervention. Int Dairy J. 2014;34(1):19-24.

24. Baar K. Nutrition and the molecular response to strength training. Sport Sci Exch. 2014;27(123):1-4.

25. Mitchell CJ, Churchward-Venne TA, West DWD, Burd NA, Breen L, Baker SK, et al. Resistance exercise load does not determine training-mediated hypertrophic gains in young men. J Appl Physiol. 2012;113(1):71-7.

26. Smith JW, Jeukendrup A. Performance nutrition for young athletes. In: Nutrition and Enhanced Sports Performance. London: Elsevier; 2014. p. 523-9.

27. Bosse JD, Dixon BM. Dietary protein to maximize resistance training: a review and examination of protein spread and change theories. J Int Soc Sports Nutr. 2012;9(1):42.

28. Lobo V, Patil A, Phatak A, Chandra N. Free radicals, antioxidants and functional foods: impact on human health. Pharmacogn Rev. 2010;4(8):118-26. 